\title{
Common errors in the slope stability analyses of tailings dams
}

\author{
B Brown Rio Tinto Technology and Innovation, Australia \\ I Gillani Rio Tinto Technology and Innovation, Australia
}

\begin{abstract}
Completing slope stability analyses using the correct methodology and correct strength characterisation for different failure modes is essential for managing the hazards associated with tailings storage facilities. Incorrect assumptions in the input to a slope stability program can provide highly precise but fundamentally incorrect Factors of Safety with significant safety and financial implications. Recent tailings dam failures, especially Mount Polley in Canada, and possibly Samarco in Brazil, have indicated that the failures are related to undrained shearing. In this case the pore water pressures that control the shear strength are not the ones that exist in situ before failure but the ones that are generated during the failure. This is unfortunately not well understood by many geotechnical engineers. Inappropriate use of drained analyses, inaccurate estimation of in situ effective stress in the application of the undrained strength analysis approach, failure to properly apply the SHANSEP technique for over and under consolidated clays, not capping the undrained strength at the drained strength and using linear strength envelopes to model rockfill are some of the other common problems encountered in slope stability analyses.
\end{abstract}

This paper illustrates how these incorrect assumptions regarding material behaviour can significantly affect the estimation of embankment stability. Examples, comparing stability assessments carried out with incorrect and correct methodologies, are presented to highlight the differences.

\section{Introduction}

Structural failures of tailings dams can occur for a variety of reasons including overtopping, piping, foundation settlement and slope failures. While all these failure mechanisms are important and equally damaging, this paper focuses on the failure modes associated with slope stability failures. In reviewing numerous tailings designs and analyses, the authors have identified numerous errors made in carrying out stability analyses of tailings dams. These errors can result in significant over-estimation of the level of safety for a facility resulting in an unrecognised level of risk. Errors can also result in significant under-estimation of the level of safety resulting in overly conservative designs.

This paper presents an overview of the geotechnical considerations that are essential in the assessment of the stability of tailings dams and provides examples that illustrate the errors that are commonly made and demonstrates the effect of these errors on the evaluation of dam safety.

\section{$2 \quad$ Failure modes}

Slope failures of tailings dams can occur under different failure modes that mobilise very different types of shear strengths, each with a different Factor of Safety (FS). For static stability, distinction needs to be made between the following three failure modes:

- Unconsolidated Undrained (UU) failure: This failure mode is typically associated with construction loading and is generally applicable for short-term conditions. The main assumption is that the increase in pore water pressures (pore pressures) during construction is equal to the added total stress leading to no change in the effective stress and no gain in shear strength. 
A special case of UU failure mode is when the construction involves unloading such as excavation or removal of a dike. This results in a decrease in total stress and in saturated soils, a decrease in effective stress.

- Consolidated Undrained shear failure: This failure mode is applicable for both short and long-term conditions. Saturated contractive materials generate excess pore pressures during shearing leading to a decrease in effective stress and shear strength - a phenomenon known as static-liquefaction. These shear induced excess pore pressures are often ignored in stability analyses resulting in an overestimation of the FS.

- Tailings storage facilities (TSFs) are known to fail under Consolidated Undrained shearing as a result of various triggers. The 2014 Mount Polley TSF failure in Canada is the most recent example of Consolidated Undrained shear failure that occurred after construction. The long-term stability of a TSF must therefore be checked using Consolidated Undrained shear strengths where normally consolidated, contractive materials are involved.

- Drained Shear failure: The main assumption in this failure mode is that the failure occurs at such a slow rate, or that the materials are dilative, which results in no excess (positive) pore pressures generated during shearing. Because TSF embankments generally involve uncompacted materials (deposited tailings) and/or normally consolidated clayey layers in foundation, which can depict contractive behaviour, the drained shear failure mode often over predicts the stability of a TSF.

"The shear strength of soils is controlled by effective stress, whether failure occurs under drained or undrained conditions" (Duncan \& Wright 2005 p. 22). The pore pressures that control initiation of failure are different than the pore pressures that control the failure process. This is especially true for contractive materials. Initiation of failure is controlled by in situ pore pressures and in situ effective stresses. Pore pressures that control the failure process are a sum of in situ pore pressures and excess pore pressures that are generated during the failure/shear process.

\section{Shear strength envelopes}

Materials can mobilise different shear strengths when sheared under different conditions. Distinction therefore needs to be made between the following three shear strength envelopes:

- Unconsolidated Undrained Strength Envelope: This strength envelope represents the undrained shear strength distribution prior to loading. It remains unchanged during and immediately after loading where excess pore pressures do not have time to dissipate.

- Consolidated Undrained Strength Envelope: This strength envelope represents the shear strength of a consolidated material that is sheared under undrained conditions. It is calculated with the knowledge of the pore pressure distribution and is typically expressed as the undrained strength ratio, $\mathrm{su}_{\mathrm{u}} / \mathrm{p}^{\prime}$. This strength envelope is typically used to evaluate the Consolidated Undrained shear failure mode. The consolidated undrained shear strength is best derived using the Undrained Strength Analysis (USA) approach of Ladd (1991).

- Effective Stress Drained Strength Envelope: This is the most commonly used strength envelope for assessing the long-term stability. This strength envelope, if used without considering the excess pore pressures that may generate during shear, would over-predict the strength of contractive, normally consolidated materials. Hence its use must be carefully evaluated when assessing stability of TSFs.

A graphical approach for calculating the consolidated undrained strength envelope from Isotropic Consolidated Undrained (CIU) triaxial test results is shown in Figure 1. 


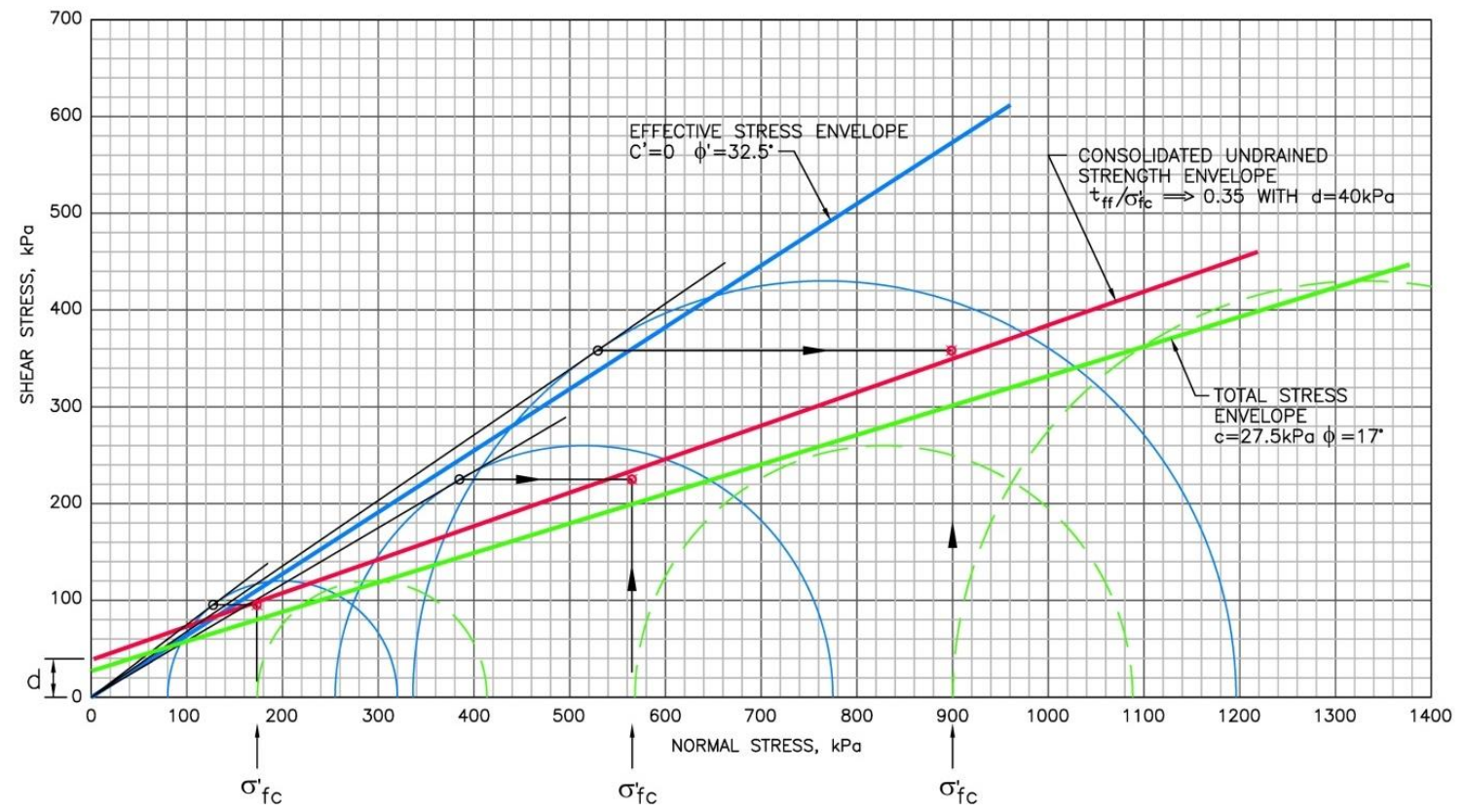

Figure 1 Consolidated undrained strength estimation from CIU triaxial test results

Triaxial compression shear tests generally provide higher strength than direct simple shear tests because of the difference in the orientation of the shear planes. For slope stability analyses, triaxial compression test results are generally used for inclined shear planes and direct simple shear test results are generally used for near horizontal shear planes. Other factors, such as an-isotropic consolidation of test specimens, can also significantly impact the shear strength measured from these tests. Engineering judgment needs to be used in the selection of the appropriate test method.

\section{Pore pressure estimation}

The majority of cases where the FS is either overestimated or underestimated relate to incorrect assessment of pore pressure conditions - incorrect pore pressures lead to incorrect effective stresses, which then lead to incorrect strength estimation. When undertaking slope stability analyses, distinction needs to be made between the following three types of pore pressures:

- In situ pore pressures: These are pore pressures that are present below the surface before initiation of failure. These include steady state pore pressures and any excess pore pressures present because of incomplete consolidation. These pressures could be hydrostatic or non-hydrostatic depending upon the drainage conditions. In situ pore pressures could be measured by field tests and/or piezometers or could even be estimated by seepage analyses.

- Loading induced excess pore pressures: These pore pressures are induced due to rapid loading of saturated materials. With time, these excess pore pressures are expected to gradually dissipate. These excess pore pressures could be measured in the field with piezometers.

- Shear induced excess pore pressures: These pore pressures are generated over and above the in situ and loading pressures during shear/failure of contractive materials. These pressures cannot be measured in the field, however, can be measured in a laboratory with an undrained shear test. Simulation of these shear induced pore pressures using constitutive soil models is possible but requires extensive calibrations to laboratory tests, which makes the whole process very complex and difficult. To overcome this, the standard practice is to adopt the USA approach, (Ladd 1991), which inherently accounts for the shear induced excess pore pressures in a practical way.

Inappropriate assessment of any one of the above three types of pore pressures could lead to erroneous FS calculation. 
Two scenarios where this occurs are:

- When a seepage only computer program, such as SEEP/W, is used to calculate pore pressures for input into a stability model for tailings that are still consolidating.

- When a phreatic surface with an assumption of hydrostatic conditions is used to estimate pore pressures for situations where the flow regime is non-hydrostatic.

\section{$5 \quad$ Estimation of tailings strength from field tests}

Field tests such as Cone Penetration Test (CPT) and/or Standard Penetration Test (SPT) are commonly used for investigating sub-surface conditions including estimation of shear strength for stability models. These tests provide only indirect estimation of shear strength parameters using correlations that are predominately developed for naturally sedimented soils. Since tailings are manufactured materials with certain unique characteristics (geochemistry, angularity etc.) the applicability of the correlations must be evaluated for site specific conditions. Comparisons with high quality laboratory strength test results is recommended to calibrate the field correlations.

\section{Methods of analysis}

Different computer programs offer different limit equilibrium methods for computing FS. Some of these methods consider all of the conditions of static equilibrium while others consider only some of them. For example, Bishop, Janbu, and Ordinary Method of Slices satisfy only some of the equilibrium requirements and hence are not recommended. Methods such as Spencer's and Morgenstern and Price's satisfy both force and moment equilibrium equations and are known to provide reliable results for both circular and non-circular shear surfaces.

The finite element/difference approaches using stress-strain relationships are also becoming very popular for estimating FS values. The two big advantages with using these approaches are:

- The critical failure mode/surface is automatically identified without having to search for it.

- The strain incompatibility issue, a major limitation in the limit equilibrium methods, could be addressed in a reasonable manner.

In the authors' experience, the finite element/difference approaches provide very similar results to those obtained from limit equilibrium methods, provided the analyses are carried out correctly.

\section{$7 \quad$ Example 1 - shear strength of under consolidated materials}

Consolidated undrained strength approach can be used for under consolidated materials if the pore pressure distribution, including the excess pore pressures, are known. Errors occur when the excess pore pressures are ignored and hydrostatic pore pressures are assumed. This assumption leads to either underestimating the strength ratio when using field tests and/or overestimating the FS in a slope stability analysis. Figure 2 illustrates the incorrect and correct approaches for estimating $s_{u} / p^{\prime}$ ratio of under consolidated tailings using CPT results. 
Incorrect approach

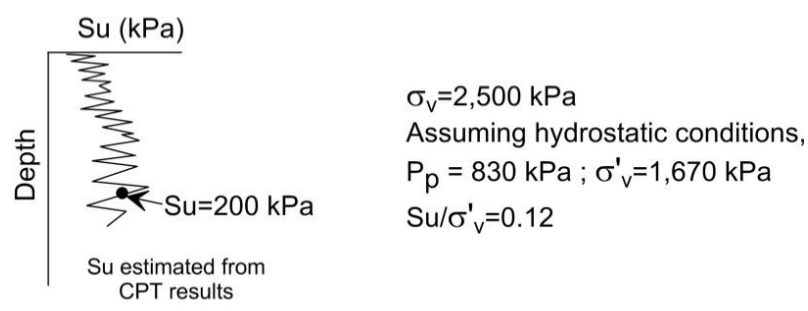

\section{Correct approach}
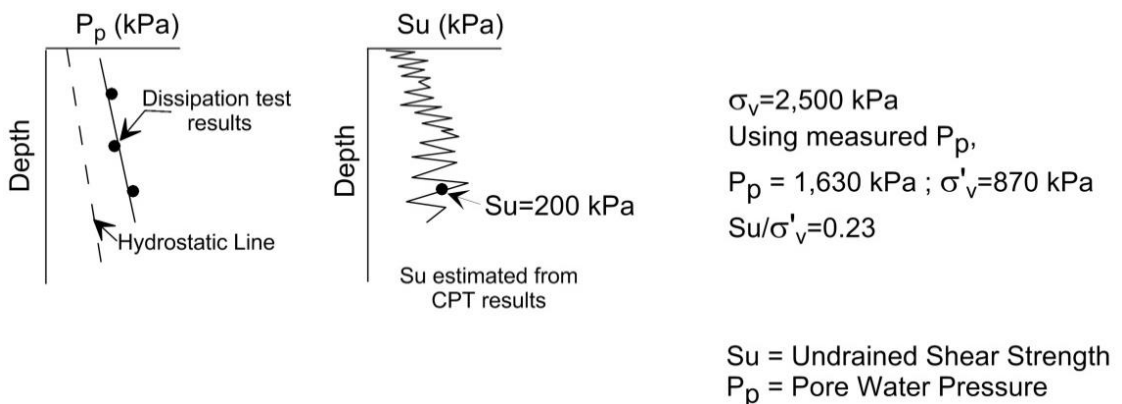

Figure 2 Incorrect and correct approaches for estimating Su/p' ratio of under consolidated tailings

\section{Example 2 - capping the undrained strength at drained strength}

An error is commonly made in the modelling of the undrained strength of a fine grained material at low confining stress. The example problem computes the undrained stability of a TSF that is underlain by a relatively thin and moderately over-consolidated clay layer. When tested in situ, the clay yields an undrained strength of $100 \mathrm{kPa}$ and a drained strength, friction angle of $28^{\circ}$. Considering that the undrained failure mode is being evaluated, designer adopts a cohesion only strength envelope for the foundation clay with $\mathrm{c}=100 \mathrm{kPa}$ and $\phi=0$. Using this approach, the FS for the $32 \mathrm{~m}$ high TSF is computed to be 1.25 as shown in Figure 3.

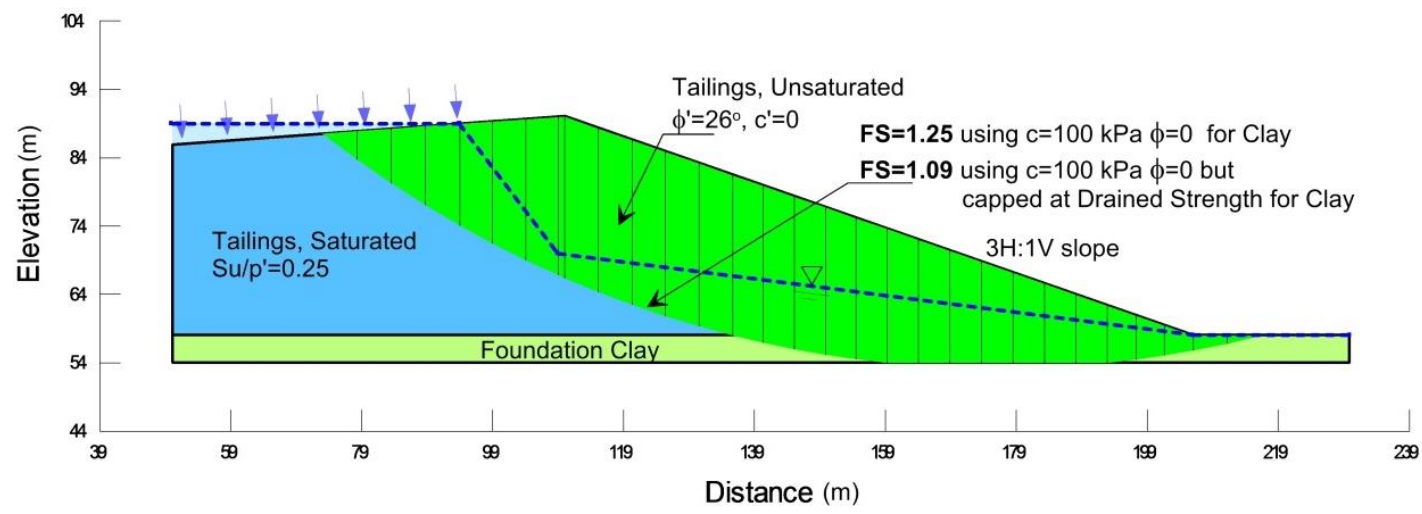

Figure 3 Undrained stability analyses for Example 1

Anywhere along the shear surface, where the drained strength is lower than the undrained strength, reliance is placed on the generation of negative pore pressures during shearing, which is why the undrained strength appears to be higher than the drained strength.

In the field, negative pore pressures can quickly dissipate leading to a reduction in the shear strength. For this reason, the undrained strength should be capped at the drained strength in the slope stability analyses, as shown in Figure 4. When the analyses were repeated using the bilinear strength envelope (Figure 4), the computed FS dropped from 1.25 to 1.09 . 


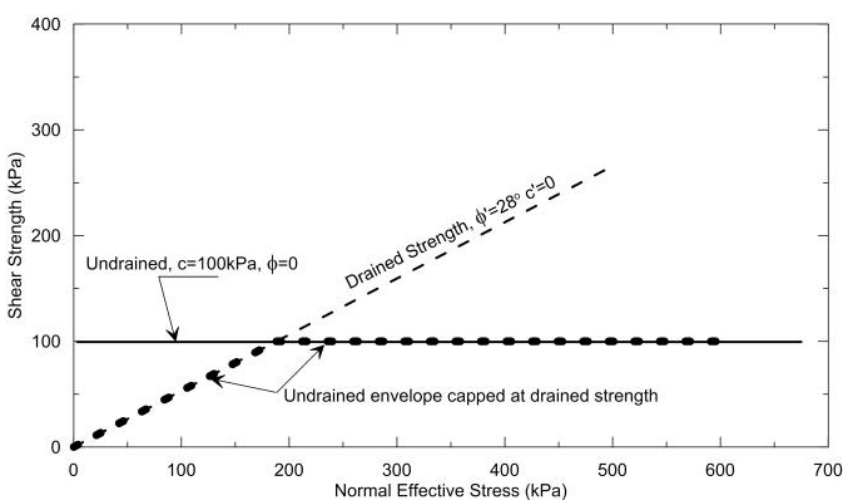

Figure 4 Capping of undrained strength at drained strength

\section{$9 \quad$ Example 3 - staged construction over saturated tailings}

This example analyses a dike construction over saturated tailings. The water table is assumed to be at the surface and the dike's final geometry is assumed to be $6 \mathrm{~m}$ high with $3 \mathrm{H}: 1 \mathrm{~V}$ batter. Fill placement over saturated tailings will generate excess pore pressures and the staged construction approach, after Ladd (1991), is utilised to maintain stability. The analyses evaluate the short-term, post-construction, unconsolidated-undrained stability and the long-term consolidated-undrained stability of the dike using correct and incorrect methodologies.

The correct methodology for the short-term construction stability accounts for the excess pore pressures that are generated due to rapid loading and also for the excess pore pressures that are generated during shear. The incorrect methodologies account for either no excess pressures or only the construction induced excess pore pressures ignoring shear induced excess pore pressures.

Stability analyses results from Stage 1 construction, which involves placing a $3 \mathrm{~m}$ high lift over tailings, are shown in Figure 5 and summarised in Table 1.

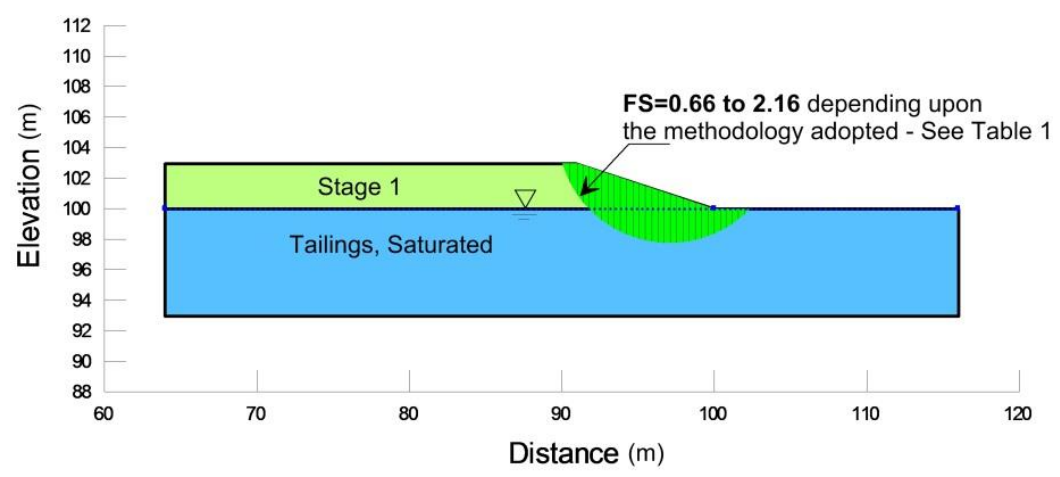

Figure 5 Model geometry and stability analyses results for Stage 1 of Example 3

Table 1 Summary of stability analyses results for Stage 1 of Example 3

\begin{tabular}{|c|c|c|c|}
\hline Methodology & Description & FS & \\
\hline $3 A$ & Sat. tailings modelled with $\phi^{\prime}=26^{\circ} \mathrm{c}=0$; With no excess pore pressures & 2.16 & Incorrect \\
\hline 3B & $\begin{array}{l}\text { Sat. tailings modelled with } \phi^{\prime}=26^{\circ} \mathrm{c}=0 \text {; With loading induced excess } \\
\left.\text { pore pressures (B-bar=1 in SLOPE } / W^{*}\right)\end{array}$ & 1.14 & Incorrect \\
\hline $3 C$ & $\begin{array}{l}\text { Sat. tailings modelled with } \mathrm{Su} / \mathrm{p}^{\prime}=0.28 \text {; With shear induced excess pore } \\
\text { pressures but no loading excess pore pressures }\left(\mathrm{B}-\mathrm{bar}=0 \text { in } \mathrm{SLOPE} / \mathrm{W}^{*}\right)\end{array}$ & 1.48 & Incorrect \\
\hline $3 D$ & $\begin{array}{l}\text { Sat. tailings modelled with } \mathrm{Su} / \mathrm{p}^{\prime}=0.28 \text {; With shear and loading induced } \\
\text { excess pore pressures }\left(\mathrm{B}-\mathrm{b} \mathrm{b}=1 \text { in } \mathrm{SLOPE} / \mathrm{W}^{*}\right)\end{array}$ & 0.66 & Correct \\
\hline
\end{tabular}

*SLOPE/W (2013) 
These results show, when both loading and shear induced excess pore pressures are not considered, the computed FS values indicate acceptable stability for post construction failure mode for the Stage 1 . When both loading and shear induced excess pore pressures are considered, the computed FS for the same failure mode is well below 1.0 .

After Stage 1 construction when excess pore pressures have dissipated, the short-term construction stability analysis (unconsolidated-undrained) for a $3 \mathrm{~m}$ Stage 2 lift gives a FS of 1.15 (Figure 6). For the long-term, consolidated-undrained failure mode for Stage 2, the computed FS is 1.34. This failure mode assumes that all construction induced excess pore pressures have dissipated. However, shear induced excess pore pressures would be generated if failure were to occur under undrained conditions and is the most likely long-term failure mode involving normally consolidated saturated tailings.

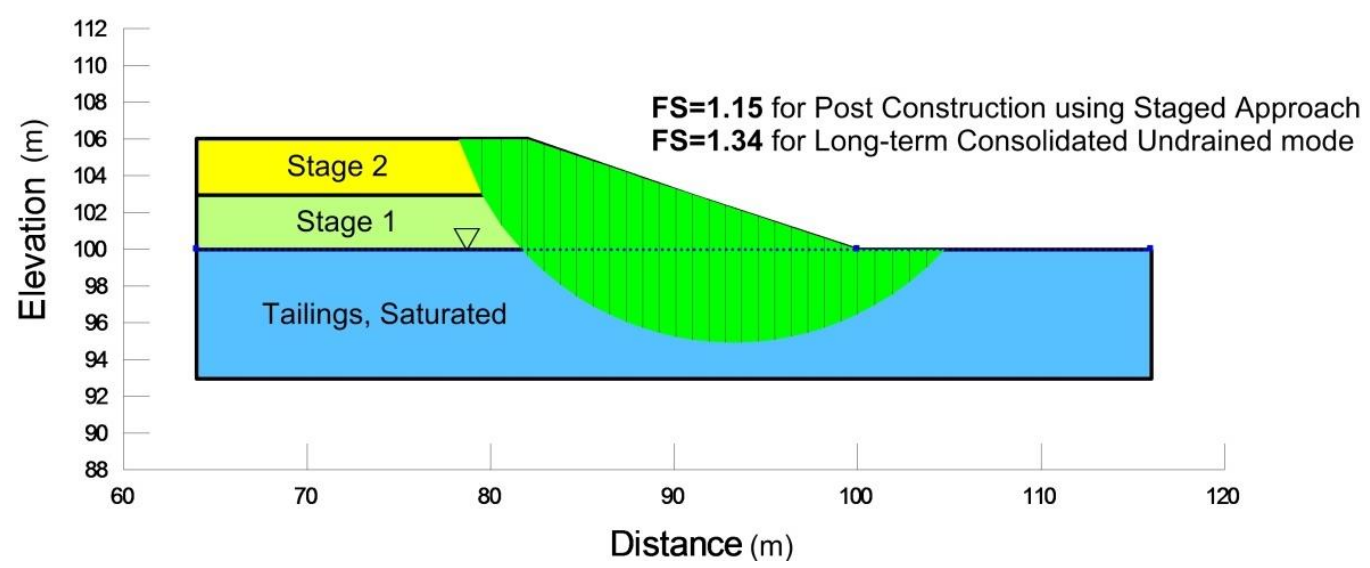

Figure 6 Model geometry and stability analyses results for Stage 2 of Example 3

The long-term drained FS for Stage 2 is computed to be 1.93. This failure mode assumes that the shearing occurs so slowly that no excess pore pressures would be generated. This would not occur for a low permeability, normally consolidated, saturated tailings which are typically expected to contract as opposed to dilate during shearing.

If the long-term FS for this example problem had been checked only for the drained shear failure, it would have indicated that the FS meets the minimum criteria of 1.5. The long-term FS for the consolidated-undrained failure mode for this structure does not meet the minimum criteria of 1.5.

\section{Example 4 - construction over over-consolidated clay foundation}

This example demonstrates the analysis of the stability of a TSF that is underlain by a layer of naturally occurring, over-consolidated clay. This is similar to the Mount Polley scenario. During the design phase, when this foundation clay is tested, it yields a high undrained strength and a high $\mathrm{s}_{\mathrm{u}} / \mathrm{p}^{\prime}$ ratio. Considering that the $\mathrm{s}_{\mathrm{u}} / \mathrm{p}^{\prime}$ ratio is higher than its drained shear friction angle, designers at times, thinking that they are being conservative, use the drained shear friction angle for the clay in the TSF design analyses. This misses the fact that, as the clay layer is loaded with construction of the TSF, its undrained strength ratio (not strength) drops with a reduction in over-consolidation ratio (OCR) as the increase in effective stress reduces the apparent OCR. This behaviour is best represented by the SHANSEP technique utilising the following equation:

$$
\left[\mathrm{s}_{\mathrm{u}} / \sigma^{\prime}{ }_{\mathrm{v}}\right]_{\mathrm{OC}}=\left[\mathrm{s}_{\mathrm{u}} / \sigma_{\mathrm{v}}^{\prime}\right]_{\mathrm{NC}} \times \mathrm{OCR}^{\mathrm{m}}
$$

where:

$$
\begin{aligned}
{\left[\mathrm{su}_{\mathrm{u}} / \sigma_{\mathrm{v}}^{\prime}\right]_{\mathrm{OC}}=} & \text { undrained strength ratio of over-consolidated material. } \\
{\left[\mathrm{s}_{\mathrm{u}} / \sigma_{\mathrm{v}}\right]_{\mathrm{NC}}=} & \text { undrained strength ratio of normally consolidated material. } \\
\mathrm{m} & =\begin{array}{l}
\text { exponent to describe effect of over-consolidation on undrained strength typically } \\
\text { taken as approximately } 0.8 .
\end{array}
\end{aligned}
$$


For this example (Figure 7), beyond normal effective stress of about $75 \mathrm{kPa}$, the undrained strength ratio of the over-consolidated foundation clay drops below its drained shear friction angle of $26^{\circ}$. And, beyond the pre-consolidation pressure of $200 \mathrm{kPa}$, the foundation clay starts to behave like a normally consolidated, contractive clay with an undrained strength ratio of 0.23 .

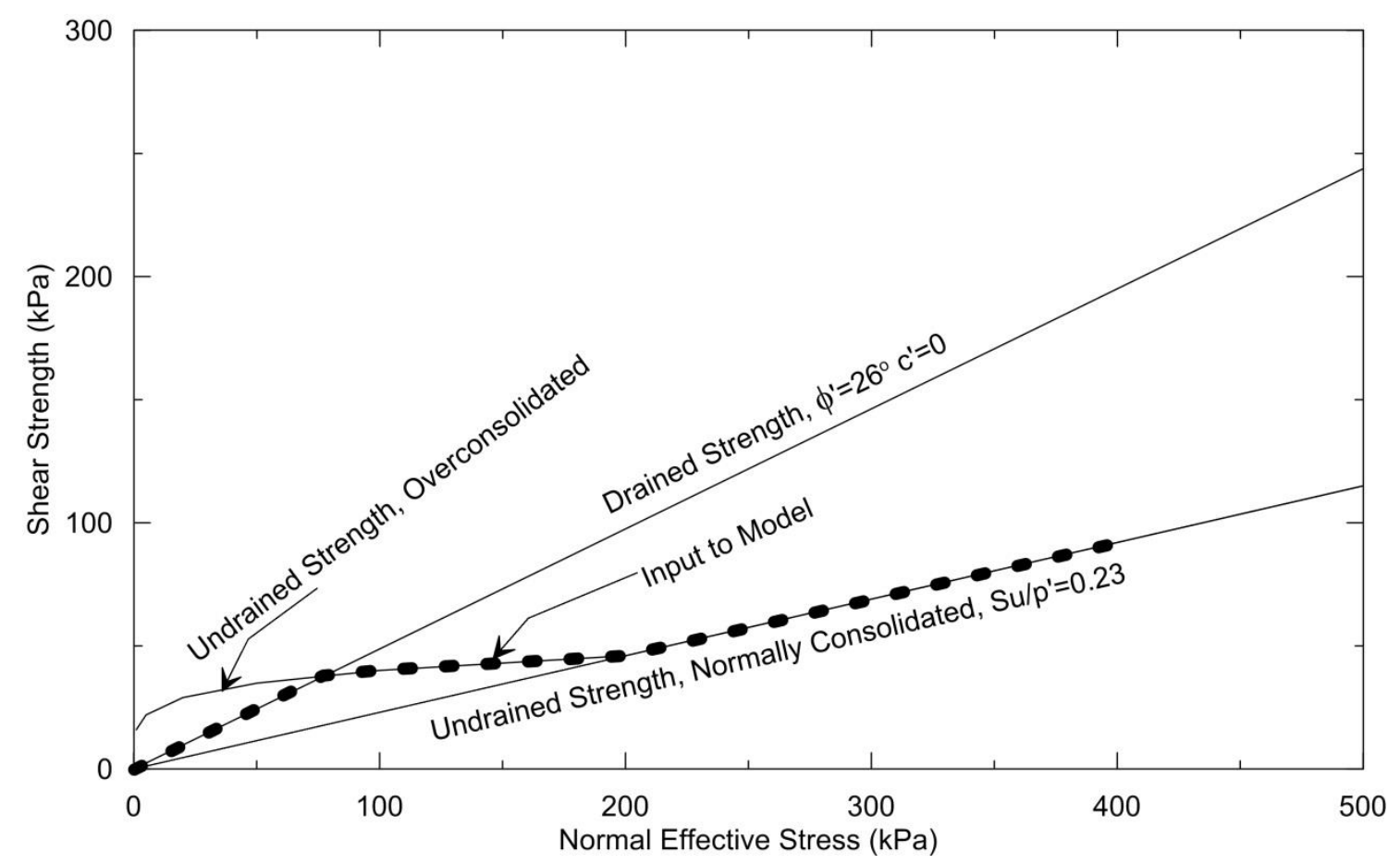

Figure 7 Strength envelopes for foundation clay

Slope stability analyses carried out for a $32 \mathrm{~m}$ high embankment, as modelled in this example, using the drained shear friction angle for the foundation clay yields a FS of 1.22 (Figure 8). The same model when rerun with the correct strength envelope yields a much lower FS of 0.7.

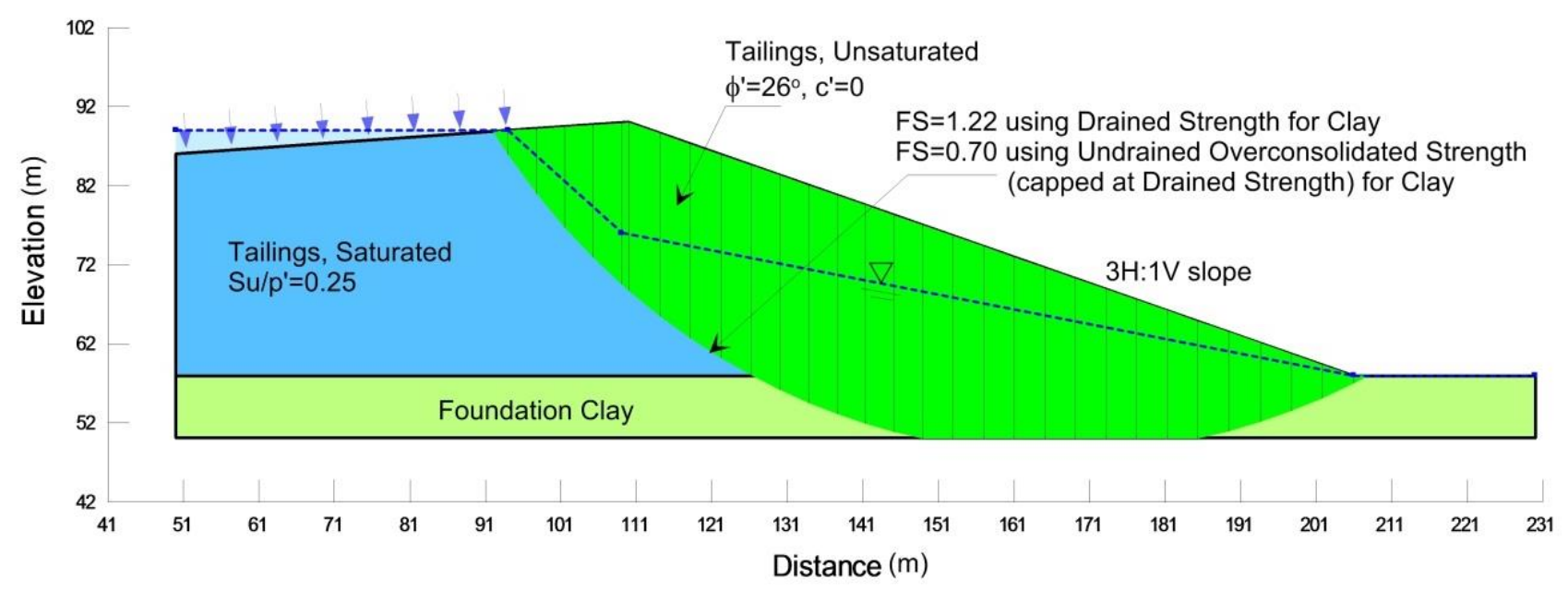

Figure 8 Results of slope stability analyses for over-consolidated clay foundation

In this and in Example 3, the issue is not with using the effective-stress-drained strength envelope. The issue is that if the effective-stress-drained strength envelope is used without considering the excess pore pressures, then the use of the envelope is wrong. 


\section{Example 5 - stability of rockfill embankment}

This example considers the characterisation of rockfill shear strength. Leps (1970) demonstrated that "the friction angle of a given rockfill decreases significantly as the normal pressure across the failure plane is increased". For an "average rockfill" Leps observed that the friction angle decreases from $55^{\circ}$ at $7 \mathrm{kPa}$ to $48^{\circ}$ at $70 \mathrm{kPa}$, a change of $7^{\circ}$ for a $63 \mathrm{kPa}$ increase in loading. Higher than normally assumed frictional strength of rockfill at low confining pressures has been found to be a substantial factor in explaining the very long term stability of low rockfill dams.

Using a single average friction angle for the entire rockfill mass, can over or under predict the computed FS values. To demonstrate this, a $32 \mathrm{~m}$ high rockfill dam with a $1.4 \mathrm{H}: 1 \mathrm{~V}$ slope is analysed using a single average friction angle of $44^{\circ}$ and reanalysed using the average rockfill strength envelope adopted from Leps (1970), (Figures 9 and 10).

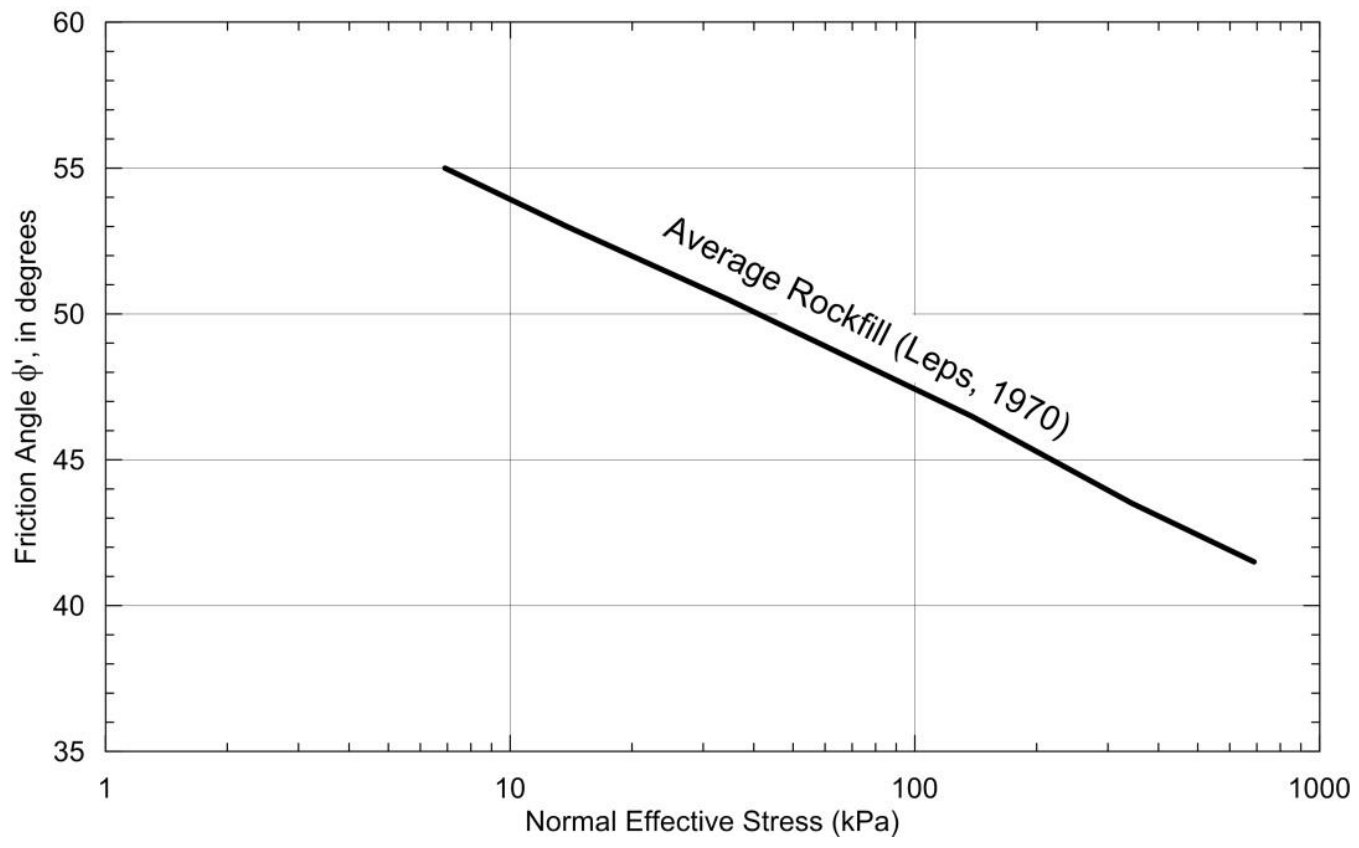

Figure 9 Change in average rockfill friction angle with normal stress from Leps (1970)

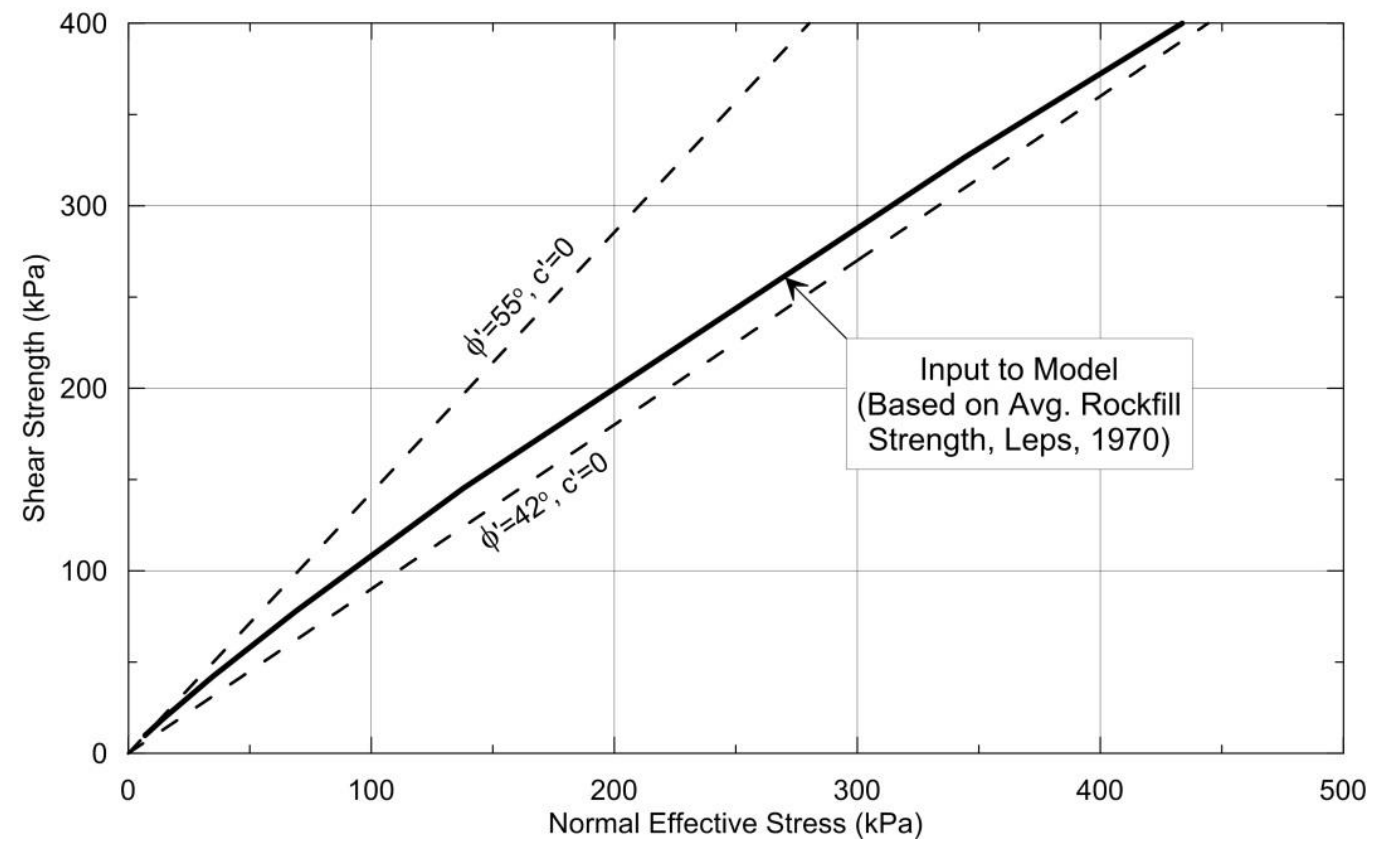

Figure 10 Rockfill strength envelope from Leps (1970) 
The results of the analyses are shown in Figure 11. Using the more rigorous rockfill strength envelope gives an acceptable FS greater than 1.5 whereas using an average friction angle results in an unacceptable FS and would result in an unnecessarily more conservative embankment slope to meet stability requirements.

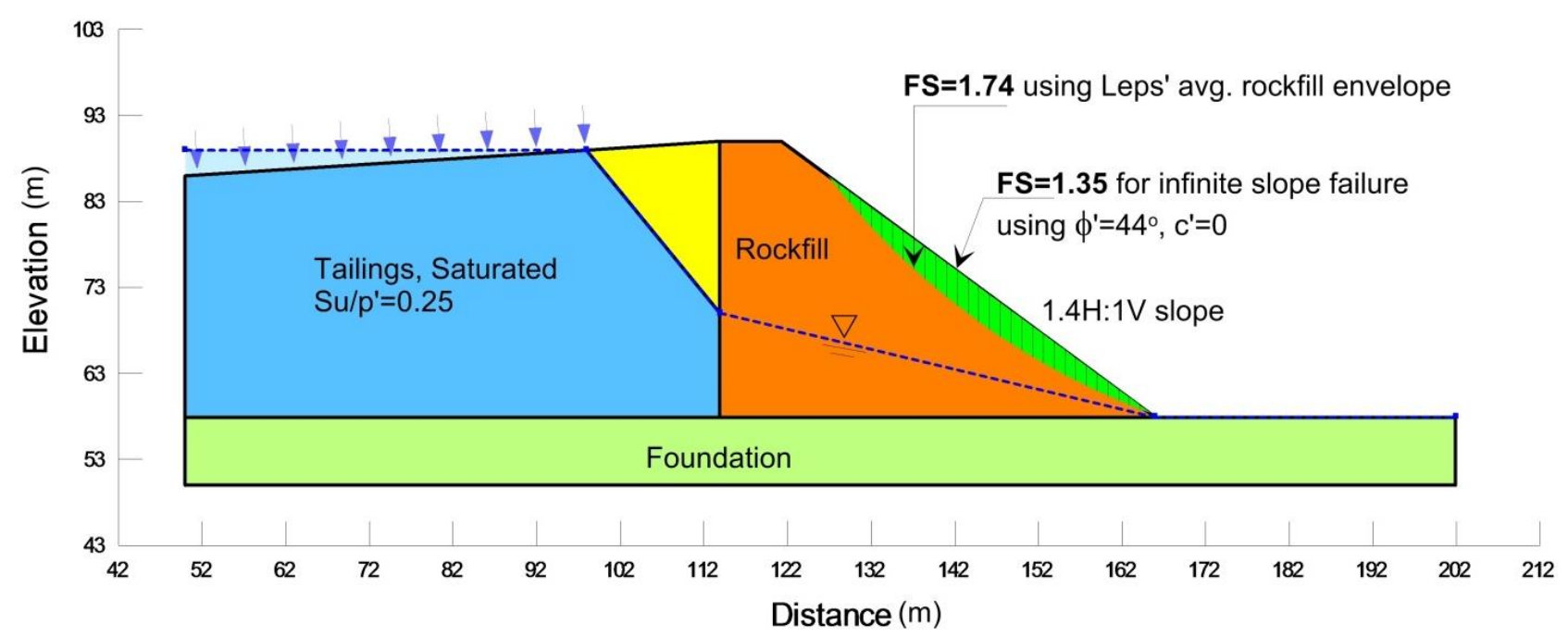

Figure 11 Analysis of a rockfill embankment

\section{Example 6 - seismic stability of a TSF with no liquefaction}

This example highlights the inappropriate use of the pseudo-static analysis in assessing the seismic stability of a TSF. It evaluates the seismic stability of a $30 \mathrm{~m}$ high TSF embankment that has been built/raised in stages. The impounded tailings have been adequately drained and consolidated and as such are not expected to liquefy for the operating basis earthquake (OBE) event with a peak ground acceleration (PGA) of $0.12 \mathrm{~g}$. Liquefaction assessment conducted using the SHAKE-91 (Idriss \& Sun 1991) computer program indicates adequate FS against liquefaction for the OBE event. Based on this finding, the pseudo-static analysis is chosen for the OBE conditions.

To account for potential remoulding of materials during shaking, the peak undrained shear strengths are arbitrarily reduced by $20 \%$ (Makdisi \& Seed 1977). The seismic coefficient for pseudo-static analysis is estimated to be two thirds of the PGA. Based on the above, the minimum FS is calculated to be 0.95 (Figure 12).

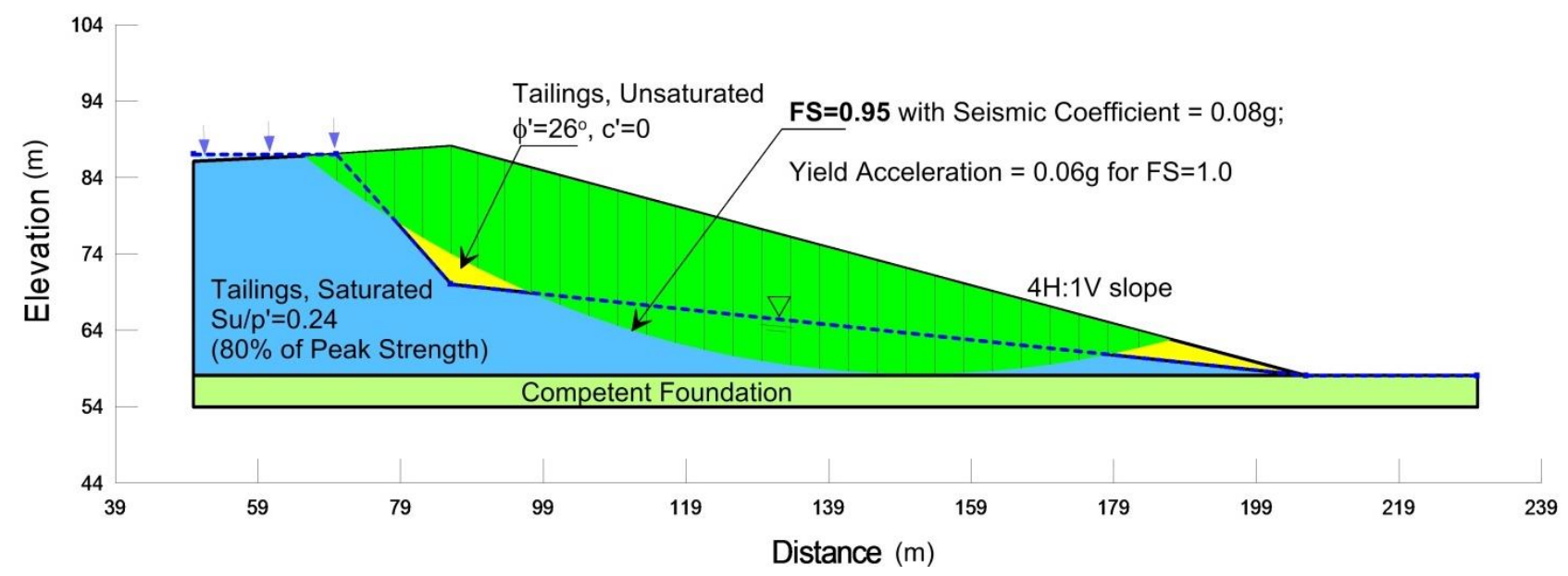

Figure 12 Results of pseudo-static analyses for OBE conditions

While the calculated FS for the pseudo-static analysis is less than 1.0, this does not automatically indicate failure. The seismic forces do not act continuously in one direction but oscillate at the earthquake frequency. The pseudo-static model is a poor representation of reality. The correct approach, in such a 
situation, is to proceed with assessing post-seismic deformations and then to evaluate whether the estimated deformations are acceptable or not. For this example, the Bray and Travasarou (2007) and Bray (2007) Simplified Seismic Displacement Procedure was used for estimating the post-seismic deformations. Inputs for the procedure for the given example are provided below:

- OBE event selected to be a 1:1,000 year event with a PGA=0.12 $\mathrm{g}$ and magnitude, $\mathrm{M}_{\mathrm{w}}=7.2$.

- Yield acceleration for the sliding mass is calculated to be $0.06 \mathrm{~g}$.

- Height of sliding wedge, $\mathrm{H},=30 \mathrm{~m}$.

- Shear wave velocity, Vs, for the impounded tailings is estimated to $120 \mathrm{~m} / \mathrm{sec}$.

- Fundamental period, $T_{s}$, of the sliding mass $=4 \mathrm{H} / \mathrm{Vs}=1 \mathrm{sec}$.

- Spectral acceleration, $\mathrm{S}_{\mathrm{a}}$, for the sliding mass for the OBE event is estimated to be $0.2 \mathrm{~g}$.

Using the above inputs and the equations provided by Bray and Travasarou (2007), the following were calculated:

- The probability of zero displacement=1\%.

- The 16 to $84 \%$ exceedance seismic displacement range $=8$ to $34 \mathrm{~cm}$.

As seen from these calculations, the post seismic deformations for the OBE event are estimated to range from 8 to $34 \mathrm{~cm}$, which for a $32 \mathrm{~m}$ high TSF embankment are expected to cause only limited and repairable damage. Hence, the stability of the given example for OBE conditions is acceptable.

\section{Example 7 - seismic stability of a TSF with potential liquefaction}

This example is the analysis of the seismic stability of a TSF with risk of liquefaction. The example entails evaluating the seismic stability of a $30 \mathrm{~m}$ high TSF embankment that has been built/raised in stages using the upstream method of construction. Tailings in the earlier stages were not adequately consolidated due to the limited size of the TSF which resulted in a high rate of rise. For the later stages, methodology was changed and mechanical equipment (mud farming) was utilised to increase the dry density of the impounded tailings.

The Maximum Design Earthquake (MDE, also called the design basis earthquake or DBE) event for this example is selected to be a 1:5,000 year event with a peak ground acceleration of $0.12 \mathrm{~g}$.

Assuming that liquefaction is not a risk, designer adopts the pseudo-static analysis approach using the reduced peak undrained strength for the saturated tailings and computes a FS of 1.12 (Figure 13).

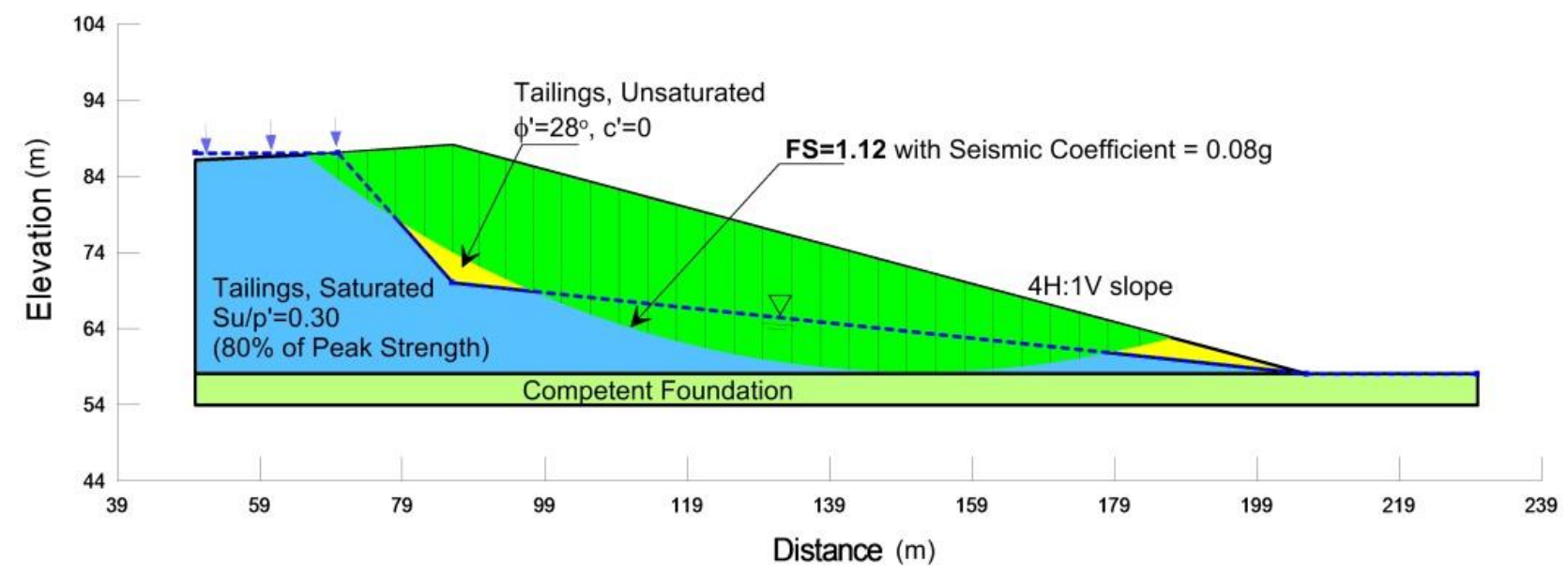

Figure 13 Results of pseudo-static analyses ignoring liquefaction 
Since the pseudo-static FS is well above 1.0, it may be believed that the seismic stability of the TSF is adequate for the MDE conditions. When the liquefaction assessment analyses are conducted using the SHAKE-91 (Idriss \& Sun 1991) computer program it indicates that the lower tailings are potentially liquefiable for the MDE event. This finding precludes the use of the pseudo-static analysis approach and necessitates evaluating the post seismic residual shear strength of the lower tailings. When the analysis is repeated, adopting the post seismic analysis approach and using residual shear strength for the lower tailings, the computed FS is well below 1.0, (Figure 14), indicating a potential flow slide and, therefore, inadequate seismic stability.

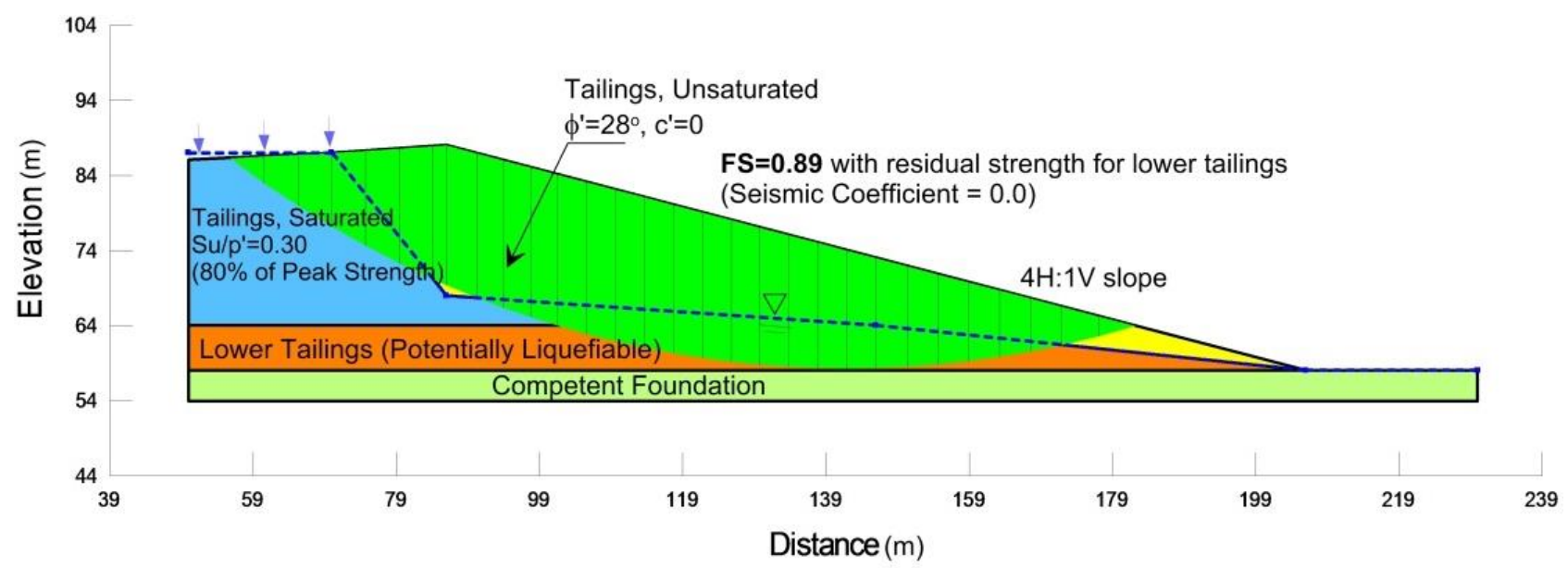

Figure 14 Results of post-seismic stability analyses considering liquefaction

\section{Conclusion}

This paper has demonstrated how incorrect assumptions regarding the failure mechanisms and shearing behaviour of the materials involved in the development of tailings dams can lead to incorrect assessment of the risk of shear failure. There have been a number of major failures in recent times where the incorrect modelling of materials has led to catastrophic failure. It is incumbent on all designers to ensure that the professionals carrying out stability assessments are fully aware of the behaviour of the materials they are analysing and how these behaviours may change with the staged development of the facilities.

\section{References}

Bray, JD 2007, 'Simplified Seismic Slope Displacement Procedures', in 4th International Conference on Earthquake Geotechnical Engineering.

Bray, JD \& Travasarou, T 2007, 'Simplified Procedure for Estimating Earthquake-Induced Deviatoric Slope Displacements', Journal of Geotechnical and Geoenvironmental Engineering, ASCE, vol. 133, no. 4, April.

Duncan, JM \& Wright, SG 2005, Soil Strength and Slope Stability, John Wiley \& Sons, Inc., New Jersey.

Idriss, IM \& Sun, JI (1991), User's manual for SHAKE-91: a computer program for conducting equivalent linear seismic response analyses of horizontally layered soil deposits.

Ladd, CC 1991, 'Stability evaluation during staged construction', Journal of Geotechnical Engineering, American Society of Civil Engineers, 117, pp. 540-615.

Leps, TM 1970, 'Review of Shearing Strength of Rockfill', Journal of the Soil Mechanics and Foundations Division, American Society of Civil Engineers, vol. 96, no. SM4, July.

Makdisi, FI \& Seed, HB 1977, A Simplified Procedure for Estimating Earthquake-Induced Deformations in Dams and Embankments, Report UCB/EERC-77/19, Earthquake Engineering Research Centre, University of California, Berkley, CA.

SLOPE/W 2013, Computer program for stability modelling. An Engineering Methodology, GEO-SLOPE International Ltd., Calgary, Alberta, Canada. 